\title{
Adverse Event MedDRA Preferred Term Code
}

National Cancer Institute

\section{Source}

National Cancer Institute. Adverse Event MedDRA Preferred Term Code. NCI Thesaurus.

Code C117384.

A coded value specifying the preferred term for the adverse event from the Medical Dictionary for Regulatory Activities (MedDRA). 